\title{
Communication architecture of an early warning system
}

\author{
M. Angermann ${ }^{1}$, M. Guenther ${ }^{2, *}$, and K. Wendlandt ${ }^{1}$ \\ ${ }^{1}$ Institute for Communications and Navigation, Deutsches Zentrum für Luft- und Raumfahrt (DLR), \\ Oberpfaffenhofen, Germany \\ ${ }^{2}$ Deutsches GeoForschungsZentrum GFZ, Telegrafenberg, 14473 Potsdam, Germany \\ *now at: Meteorological, Climatological and Geophysical Agency of Indonesia (BMKG), Jakarta, Indonesia
}

Received: 21 May 2010 - Revised: 6 September 2010 - Accepted: 7 September 2010 - Published: 2 November 2010

\begin{abstract}
This article discusses aspects of communication architecture for early warning systems (EWS) in general and gives details of the specific communication architecture of an early warning system against tsunamis. While its sensors are the "eyes and ears" of a warning system and enable the system to sense physical effects, its communication links and terminals are its "nerves and mouth" which transport measurements and estimates within the system and eventually warnings towards the affected population. Designing the communication architecture of an EWS against tsunamis is particularly challenging. Its sensors are typically very heterogeneous and spread several thousand kilometers apart. They are often located in remote areas and belong to different organizations. Similarly, the geographic spread of the potentially affected population is wide. Moreover, a failure to deliver a warning has fatal consequences. Yet, the communication infrastructure is likely to be affected by the disaster itself. Based on an analysis of the criticality, vulnerability and availability of communication means, we describe the design and implementation of a communication system that employs both terrestrial and satellite communication links. We believe that many of the issues we encountered during our work in the GITEWS project (German Indonesian Tsunami Early Warning System, Rudloff et al., 2009) on the design and implementation communication architecture are also relevant for other types of warning systems. With this article, we intend to share our insights and lessons learned.
\end{abstract}

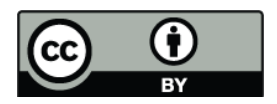

Correspondence to: M. Angermann (michael.angermann@dlr.de)

\section{Introduction}

"The objective of people-centred early warning systems is to empower individuals and communities threatened by hazards to act in sufficient time and in an appropriate manner to reduce the possibility of personal injury, loss of life and damage to property and the environment".

Source: United Nations International Strategy for Disaster Reduction (UN-ISDR, 2006a).

The 2004 Sumatra-Andaman earthquake triggered a devastating tsunami along coastlines of the Indian Ocean. The unbearable large number of casualties caused by this tsunami motivated a major effort to implement a novel warning system. In order to significantly reduce the number of casualties caused by future events, this warning system would help to evacuate affected regions by providing timely warnings.

This warning system would be equipped with a host of sensors and a decision support system based on latest seismological expertise, bathymetry and detailed information about the coastlines to deliver adequate and timely warnings to each affected individual (Fig. 1). In its essence, such an early warning system uses measurements of physical effects, such as vibration or pressure to infer about the possibility and severity of a tsunami and to derive the measures that are likely to minimize the number of casualties.

For this purpose sensors are used to obtain measurements of the physical effects. Due to the fact that the physical phenomena of earthquakes and possible tsunamis are spread over very large ranges, the sensors to measure them have to be deployed over very large regions. The process of inferring about the actual state of the world, such as whether an earthquake has caused a tsunami, needs to take all relevant

Published by Copernicus Publications on behalf of the European Geosciences Union. 


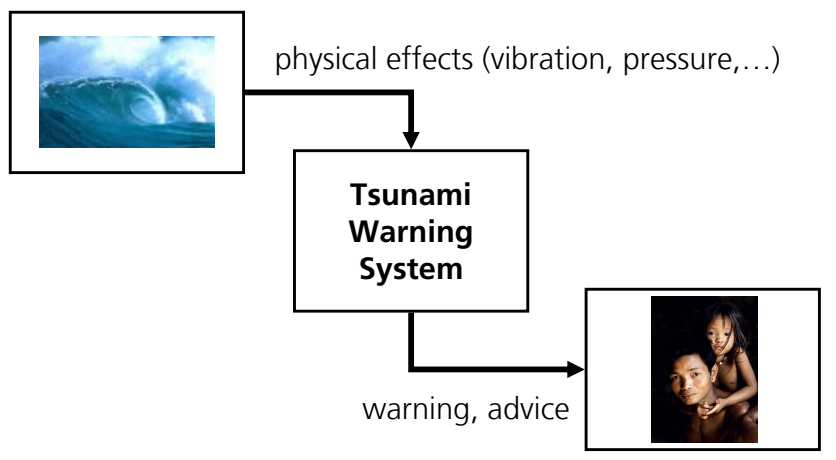

Fig. 1. In its very essence a Tsunami Warning system converts physical effects related to a Tsunami, such as vibration or pressure to adequate and timely warnings and advice to individuals.

measurements into account. Therefore, these measurements have to be reliably transmitted to a location where this automated or semi-automated inference process is happening. Figure 2 depicts a generic model for the "convergent" section of a warning system that is responsible for collecting and delivering sensor data to a central alert or warning center. A more detailed discussion of this part in GITEWS is given in Sect. 3.

Once decisions about the warning levels and the regions that should be warned are made, the warnings have to be send to the individuals in these supposedly affected regions. The UN- ISDR checklist (see references) for developing early warning systems lists four prerequisites for effective warning:

- "Communication and dissemination systems tailored to the needs of individual communities (e.g. radio or television for those with access; and sirens, warning flags or messenger runners for remote communities)."

- "Warning communication technology reaches the entire population, including seasonal populations and remote locations."

- "International organizations or experts consulted to assist with identification and procurement of appropriate equipment."

- "Multiple communication mediums used for warning dissemination (e.g. mass media and informal communication)."

A generic model for the "divergent" section of warning system is given in Fig. 3. It shows the use of multiple and diverse channels to reach individuals that possess or are within reach of various user devices. Section 5 discusses some general aspects of this part.

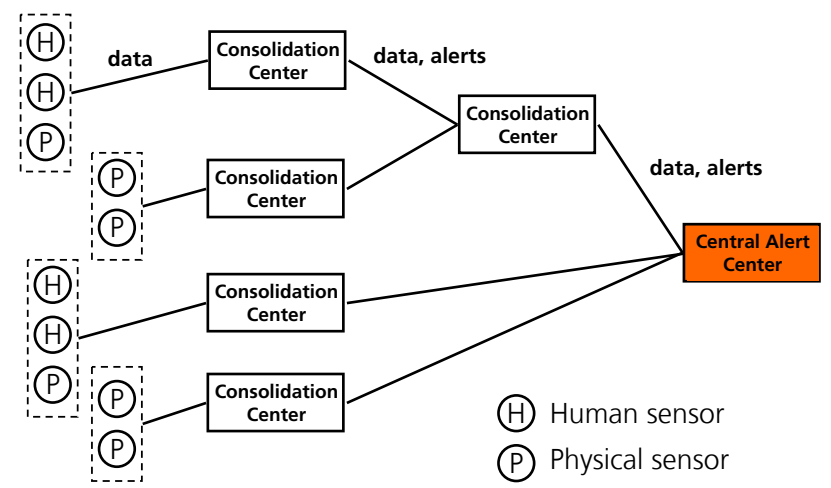

Fig. 2. Convergent section of a warning system. Information from both human and physical sensors is forwarded towards a central warning center.

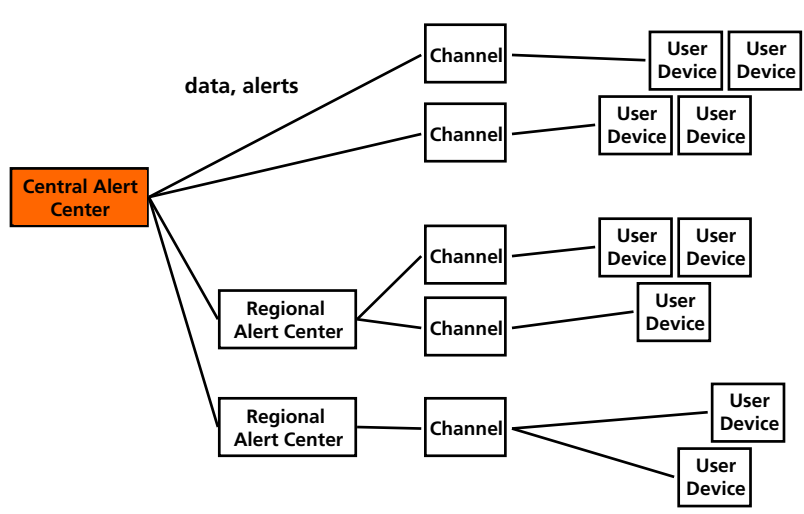

Fig. 3. Divergent section of a warning system. Warnings are delivered to individuals via multiple and diverse channels to maximize the number of successfully warned persons.

\section{Criticality and vulnerability}

The effectiveness of an early warning system relies on the tight integration of geographically distributed system components such as sensors and warning center(s). As such, an early warning system follows a distributed architecture. In any distributed system a reliable communication infrastructure forms the backbone of this distributed architecture.

\subsection{Primary tasks}

In addition to the "hot" warning chain, efficient online data exchange, assistance and monitoring capabilities between German and Indonesian partners is essential during the buildup and initial operational phases of the warning system.

Therefore, the communication infrastructure for GITEWS has to fulfill three primary tasks: 
- First, sensor communication i.e.; measurement data transport to the warning center(s) from the "field".

- Second, center-to-center communication, i.e. direct communication between experts, between warning centers and/or development and testing sites.

- Third, last mile communication: transport warning and alarms to the general public ${ }^{1}$.

\subsection{Robustness of the internet}

Most people ascribe a very high degree of robustness to the Internet. Our daily experience with telephony and Internet services that fail extremely rarely, apparently justifies this notion. In fact the Internet in general is surprisingly resistant to partial failures. Following this argument, a warning system's communication could or even should be based on the public Internet.

However, certain elements of the network are critical and severe degradation or total loss of connectivity may occur if they fail. The following description illustrates this vulnerability (19 December 2008, Bloomberg):

\begin{abstract}
"internet and telephone communications between the Middle East and Europe were disrupted after three undersea cables connecting Italy and Egypt in the Mediterranean Sea were damaged.
\end{abstract}

The failures cut the flow of "data of various kinds" between Europe and the Middle East, and there's no timeframe for when communications will be restored, said Sanjeev Gaur, director of assurance at Reliance Globalcom Ltd. in India. France Telecom $S A$, which plans to send a maintenance boat to fix the problem, said the situation should be back to normal by 31 December.

Three cable systems carrying more than 75 percent of traffic between the Middle East, Europe and America were damaged, according to the UK's Interoute Plc, which operates a fiber-optic data network connecting 92 cities. The cables run from Alexandria in northern Egypt to Sicily in southern Italy. In January, an anchor severed the cables outside Alexandria after bad weather conditions forced ships to moor off the coast" (see also references).

\footnotetext{
${ }^{1}$ Implementation of this third task was explicitly not part of the authors' tasks within the GITEWS project. Nevertheless a successful system design needs to consider relevant aspects of this task in order to understand the overall system functionality. Important work on using sirens for alarming the general public has been carried out by GTZ (German Agency for Technical Cooperation) within GITEWS - see also Spahn et al. (2010)
}

\subsection{Robustness of Indonesian communication infrastructure}

Since the communication links of a warning system are absolutely essential for its functioning, we analyze the vulnerability of the existing communication infrastructure in Indonesia in the following.

As part of the Early Warning and Mitigation System (EWMS) in the framework of the German Indonesian Tsunami Early Warning System Project (GITEWS), several, geographically distributed system components such as sensors and warning centers are foreseen to closely collaborate in real-time, thus forming a distributed architecture. To fulfill the overall system's mission, a reliable communication infrastructure forms the backbone of this distributed architecture. Furthermore, it is considered necessary to provide online data exchange, assistance and monitoring capabilities between German and Indonesian partners during the buildup and initial operational phases of the warning system. As much as this capability is essential during the build-up phase, it is important to remove any dependability on German assets in the operational phase in order to achieve full autonomy of the Indonesian authorities in operating the system.

Indonesian infrastructures, such as the electric grid, landline and sea-cables, switching centers or Internet exchanges are by definition exposed to natural disaster occurring in or around Indonesia. These infrastructures are potentially either directly affected by the natural disaster or by resulting cascading effects, such as failure of switching centers due to power outage or overload due to increased public user demand.

An exhaustive analysis of these effects and their dependencies within the Indonesian infrastructures, in order to assess their likely availability before, during and after a natural disaster, would be an interesting and valuable undertaking. However, it was neither considered to be feasible, nor within the scope of the GITEWS project. Therefore, a more pragmatic approach was necessary to assess whether the public Internet could serve as a cost-efficient and reliable communication backbone for the Early Warning and Mitigation System.

We therefore considered it meaningful to observe the response of the Indonesian public Internet under conditions that resemble the real operational conditions of the EWMS, namely a very strong earthquake.

While, in general, it is fortunate, that natural disasters, such as very strong earthquakes are rare events that occur only several times in a decade or even century, this fact is likely to prevent us from observing such strong earthquakes within the time-window available for the design of the communication infrastructure. Nevertheless, we have been monitoring publicly available Earthquake information provided by GFZ, German Research Centre for Geosciences and USGS (United States Geological Survey) in order to trigger a first 
Table 1. Relevant Earthquakes in the Indian Ocean region from 26 to 27 May.

\begin{tabular}{lllll}
\hline Date & Time & Magnitude & Location & Region \\
\hline $2006-05-27$ & $07: 35: 08$ & 5.3 & $6.22^{\circ} \mathrm{S} 130.52^{\circ} \mathrm{E}$ & Banda Sea \\
$2006-05-27$ & $04: 21: 57$ & 4.7 & $8.14^{\circ} \mathrm{S} 110.30^{\circ} \mathrm{E}$ & Java, Indonesia \\
$2006-05-27$ & $03: 10: 06$ & 5.1 & $8.42^{\circ} \mathrm{S} 110.14^{\circ} \mathrm{E}$ & Java, Indonesia \\
$2006-05-26$ & $22: 54: 02$ & 5.8 & $8.04^{\circ} \mathrm{S} 110.43^{\circ} \mathrm{E}$ & Java, Indonesia \\
\hline
\end{tabular}

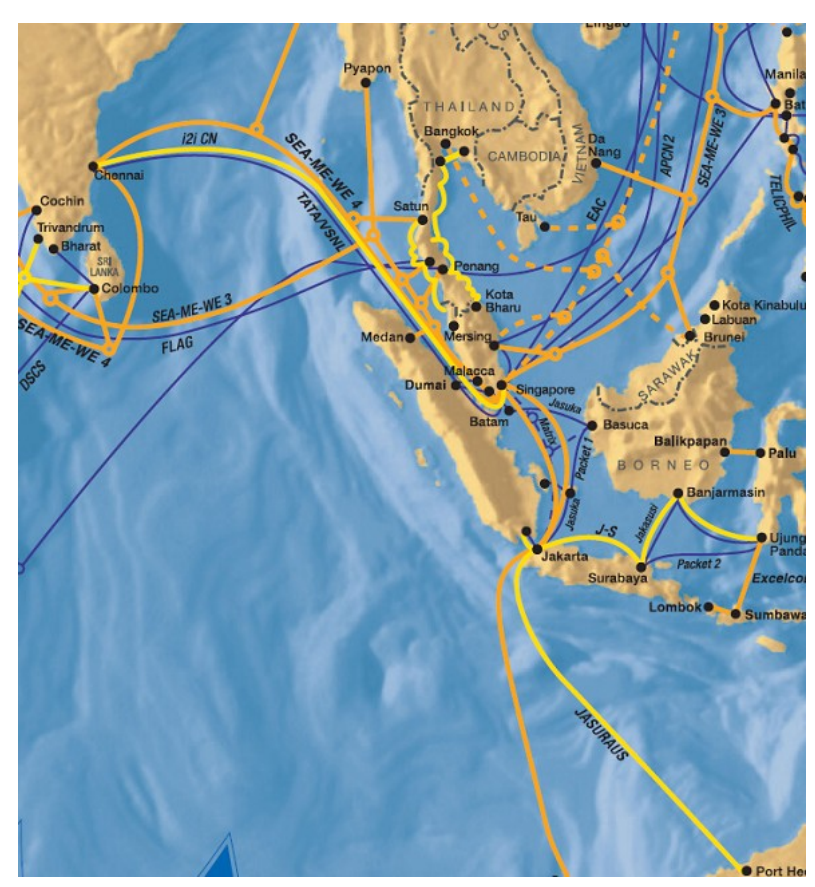

Fig. 4. Sea cables available for communications to/from Indonesia. Source: Alcatel-Lucent, Worldmap of optical fibre submarine networks, 2007.

network analysis from hosts outside Indonesia with respect to reachability of hosts inside Indonesia.

Indonesia has many small Internet service providers (ISPs) providing Dialup and DSL (digital subscriber line) connectivity in many parts of the country. GSM (Global System for Mobile Communications) mobile network operators offer GPRS (General Packet Radio Services) based Internet Access, too.

Although we lack exact data, we found only few major carriers, namely Indosat, Satelindo, Telkom and cbn that provided access ("upstream") to the core Internet at the beginning of the project in 2005.

All providers hold sea-cable based links to locations all over Indonesia and to Singapore (see Fig. 4). They also hold a single satellite link to a Los Angeles based ISP called CAIS.

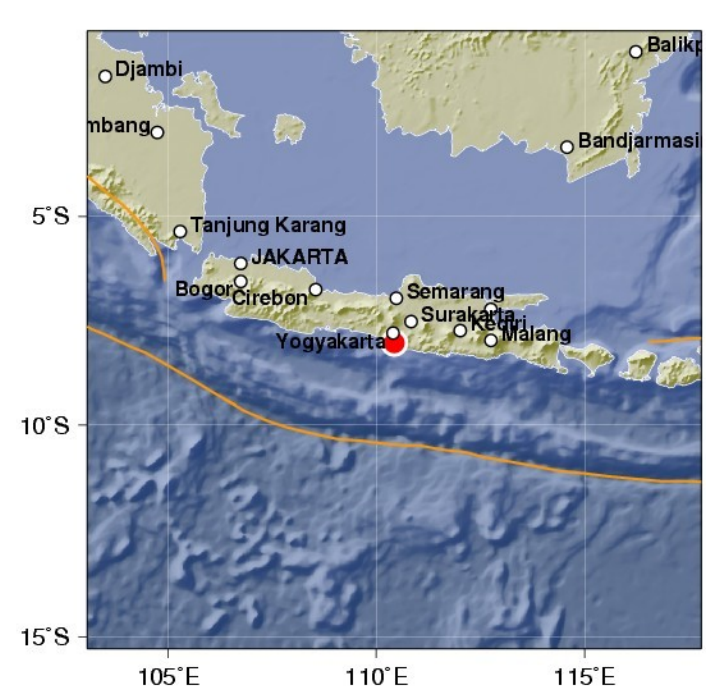

Fig. 5. Map of Java with earthquake localized near Yogyakarta. Source: GEOFON/GFZ Potsdam.

\section{Empirical evidence}

In 2005, there was a central Internet Exchange Point OpenIXp.net linking some 100 local ISPs of Indonesia. BMKG (Badan Meteorologi Klimatologi dan Geofisika) was connected via 2 DSL lines with $1.5 \mathrm{Mbit} / \mathrm{s}$ in total. Local traffic included local internet access for employees, web-server with public access and access to remote seismic networks.

We conducted an evaluation of the the reachability of Indonesian hosts using the following two IP-addresses given by BMKG: 202.69.107.133 (gis.bmg.go.id) and 202.162.217.4 (intranet portal of BMKG). A notification about an earthquake near Yogyakarta on 26 May 2006, had triggered us to probe the reachability of these hosts.

Time, location and magnitude of this and following earthquakes in the Indian Ocean region had been determined by the GeoFon network of GFZ and are given in Table 1 as well as depicted on a map in Fig. 5.

Probing of the Internet connectivity was performed in the morning, approximately $8 \mathrm{~h}$ after the first earthquake. The probing has been performed using a standard traceroute tool from three different hosts from within DFN (Deutsches Forschungsnetz), a commercial ISP and from a host in Singapore in order to provoke different routes. The 
Table 2. Traced route originating from host in Oberpfaffenhofen, Germany within DFN (Deutsches Forschungsnetz) towards host at BMKG's Jakarta premises in Indonesia on 26 May, approx. 06:30 UTC. The trace shows that the route is broken at the hop towards Indonesia, thus rendering Indonesia unreachable from within DFN. A router in Los Angeles is the last reachable hop in this trace. For illustration purposes the remainder of the route is added and marked red, based on a trace several weeks after the earthquake.

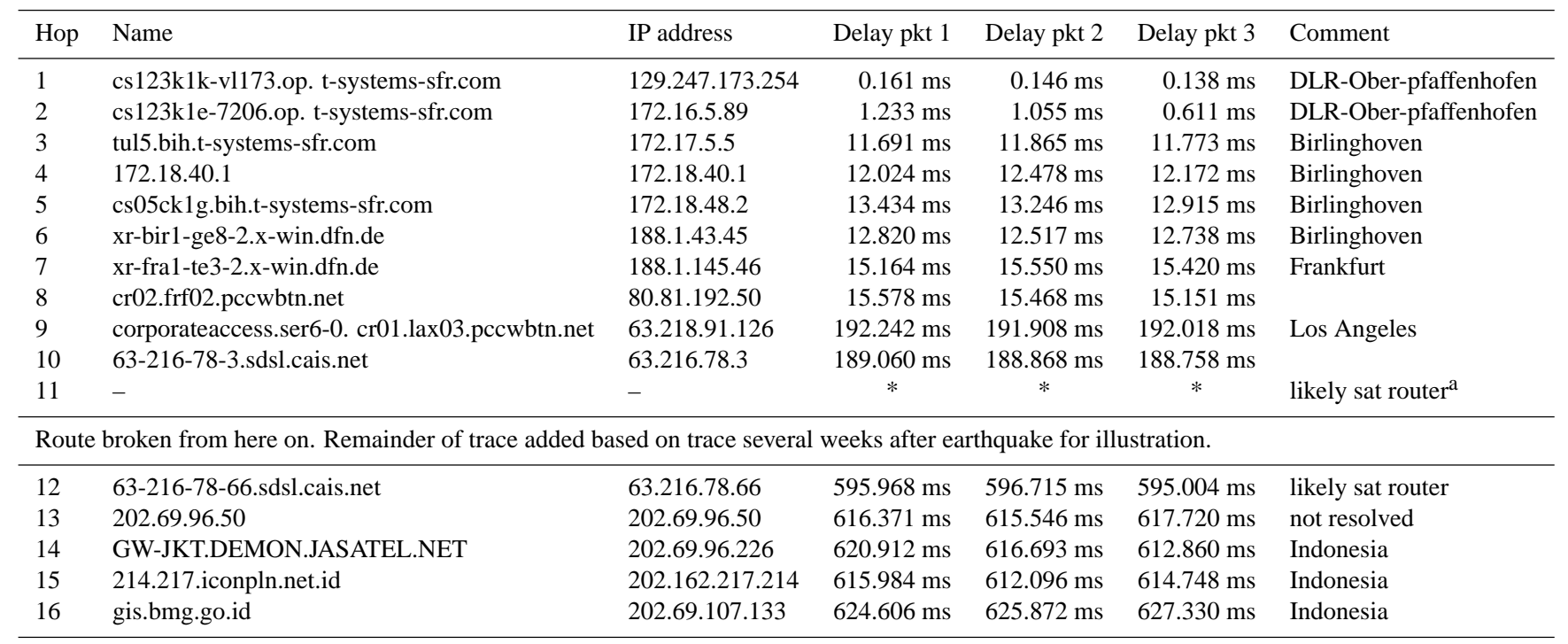

a Satellite path delay is approximately 270 milliseconds (the time required for the signal to travel $35,800 \mathrm{~km}$ into space and return). If associated signal processing time through baseband equipment is included, total path delay is closer to 320 milliseconds.

Table 3. Traced route originating from DE-CIX a commercial Internet Exchange of German ISPs towards host at BMKG's Jakarta premises in Indonesia on 26 May, approx. 06:30 UTC. The trace shows that the route is broken at the hop towards Indonesia, thus rendering Indonesia unreachable from commercial ISP networks. A router in Los Angeles is the last reachable hop in this trace. For illustration purposes the remainder of the route is added and marked red, based on a trace several weeks after the earthquake.

\begin{tabular}{|c|c|c|c|c|c|c|}
\hline Hop & Name & IP address & Delay pkt 1 & Delay pkt 2 & Delay pkt 3 & Comment \\
\hline 1 & fragw.gatewayrouter.net & 84.16 .224 .1 & $0.891 \mathrm{~ms}$ & $0.629 \mathrm{~ms}$ & $0.620 \mathrm{~ms}$ & \\
\hline 2 & fragw1.gatewayrouter.net & 217.20.117.10 & $0.279 \mathrm{~ms}$ & $0.229 \mathrm{~ms}$ & $0.250 \mathrm{~ms}$ & \\
\hline 3 & cr02.frf02.pccwbtn.net & 80.81 .192 .50 & $0.680 \mathrm{~ms}$ & $0.783 \mathrm{~ms}$ & $0.630 \mathrm{~ms}$ & \\
\hline 4 & corporateaccess.ser6-0. cr01.lax03.pccwbtn.net & 63.218 .91 .126 & $176.450 \mathrm{~ms}$ & $173.370 \mathrm{~ms}$ & $174.652 \mathrm{~ms}$ & \\
\hline 5 & 63-216-78-3.sdsl.cais.net & 63.216 .78 .3 & $175.502 \mathrm{~ms}$ & $176.128 \mathrm{~ms}$ & $172.903 \mathrm{~ms}$ & likely sat router \\
\hline 6 & - & - & $*$ & $*$ & $*$ & \\
\hline \multicolumn{7}{|c|}{ Route broken from here on. Remainder of trace added based on trace several weeks after earthquake for illustration. } \\
\hline 7 & 63-216-78-66.sdsl.cais.net & 63.216 .78 .66 & $566.217 \mathrm{~ms}$ & $564.771 \mathrm{~ms}$ & $558.930 \mathrm{~ms}$ & likely sat router \\
\hline 8 & 202.69.96.50 - 20 & 202.69.96.50 & $493.803 \mathrm{~ms}$ & $482.275 \mathrm{~ms}$ & $492.839 \mathrm{~ms}$ & not resolved \\
\hline 9 & GW-JKT.DEMON.JASATEL.NET & 202.69.96.226 & $485.346 \mathrm{~ms}$ & $484.928 \mathrm{~ms}$ & $503.168 \mathrm{~ms}$ & Indonesia \\
\hline 10 & 214.217.iconpln.net.id & 202.162 .217 .214 & $493.944 \mathrm{~ms}$ & $486.860 \mathrm{~ms}$ & $490.326 \mathrm{~ms}$ & Indonesia \\
\hline 11 & www.bmg.go.id & 202.69.107.133 & $533.261 \mathrm{~ms}$ & $538.869 \mathrm{~ms}$ & $534.448 \mathrm{~ms}$ & Indonesia \\
\hline
\end{tabular}

host (gis.bmg.go.id, 202.69.107.133) operated by BMKG in Jakarta has been selected as endpoint of the traces. The resulting traces are listed and annotated in the following three Tables 2-4. While we were not able to determine the actual mechanism that led to this interruption, this event hinted that an earthquake may have detrimental effects on the communication infrastructure in Indonesia.

\section{Sensor communication}

Due to the large number and wide spatial spread of GITEWS' sensors (seismic and GPS stations, tide gauges, and buoys) the design, implementation and operation of the converging segment of the warning chain (see Fig. 2 in Sect. 1) is particularly challenging. It became clear in a very early phase of 
Table 4. Traced route via Singapore (sea-cable operated by Singapore Telecom towards Indonesia) towards host at BMKG's Jakarta premises in Indonesia on 26 May, approx. 06:30 UTC. The trace shows that the route is broken at the hop towards Indonesia, thus rendering Indonesia unreachable from commercial ISP networks using this route. For illustration purposes the remainder of the route is added and marked red, based on a trace several weeks after the earthquake.

\begin{tabular}{lllccc}
\hline Hop & Name & IP address & Delay pkt 1 & Delay pkt 2 & Delay pkt 3 \\
\hline 4 & fa8-1-0.sinar3.Singapore.opentransit.net & 193.251 .128 .209 & $\begin{array}{c}2.882 \mathrm{~ms} \\
*\end{array}$ & $\begin{array}{c}1.370 \mathrm{~ms} \\
*\end{array}$ & $\begin{array}{c}1.758 \mathrm{~ms} \\
*\end{array}$ \\
\hline & - & - & & \\
\hline \multicolumn{2}{l}{ Route broken from here on. Remainder of trace added based on trace several weeks after earthquake for illustration. } \\
\hline 6 & 202.93 .46 .113 & 202.93 .46 .113 & $13.471 \mathrm{~ms}$ & $13.541 \mathrm{~ms}$ & $13.281 \mathrm{~ms}$ \\
7 & 202.155 .7 .252 & 202.155 .7 .252 & $14.038 \mathrm{~ms}$ & $14.013 \mathrm{~ms}$ & $13.780 \mathrm{~ms}$ \\
8 & 202.155.137.18 & 202.155 .137 .18 & $14.798 \mathrm{~ms}$ & $13.704 \mathrm{~ms}$ & $13.337 \mathrm{~ms}$ \\
9 & 202.155.27.27 & 202.155 .27 .27 & $13.961 \mathrm{~ms}$ & $21.561 \mathrm{~ms}$ & $16.666 \mathrm{~ms}$ \\
10 & Fe-2-1.int-core-noc.BORG.JASATEL.NET & 202.69 .96 .213 & $17.588 \mathrm{~ms}$ & $17.155 \mathrm{~ms}$ & $16.278 \mathrm{~ms}$ \\
11 & Ge-1-1.edge1-core-noc.ZEUS.JASATEL.NET & 202.69 .96 .210 & $19.563 \mathrm{~ms}$ & $18.199 \mathrm{~ms}$ & $18.200 \mathrm{~ms}$ \\
12 & Ge-1-1.Edge3-core-noc.ZOPE.JASATEL.NET & 202.69 .96 .218 & $21.534 \mathrm{~ms}$ & $17.486 \mathrm{~ms}$ & $17.828 \mathrm{~ms}$ \\
13 & GW-JKT.DEMON.JASATEL.NET & 202.69 .96 .226 & $19.131 \mathrm{~ms}$ & $18.299 \mathrm{~ms}$ & $16.819 \mathrm{~ms}$ \\
14 & 214.217.iconpln.net.id & 202.162 .217 .214 & $20.386 \mathrm{~ms}$ & $20.065 \mathrm{~ms}$ & $19.767 \mathrm{~ms}$ \\
15 & www.bmg.go.id & 202.69 .107 .133 & $37.698 \mathrm{~ms}$ & $33.952 \mathrm{~ms}$ & $27.449 \mathrm{~ms}$ \\
\hline
\end{tabular}

the project that due to the remoteness of many sensor stations and the vulnerability of existing landlines, satellite communication would be the only viable option to connect the sensors to the central warning center in Jakarta.

\subsection{Choice of satellite communication system}

Satellite systems may operate without the need for any fixed terrestrial infrastructure in the coverage area by using onboard switching and thereby allowing mobile terminals to directly communicate with each other via the space segment. A typical example of this type of system is Iridium (see http://www.iridium.com/). The Iridium satellite constellation currently comprises 66 active satellites used for worldwide voice and data communication, mostly from hand-held satellite phones. These satellites are deployed in six polar low earth orbital planes at a height of approximately $780 \mathrm{~km}$ and communicate with neighboring satellites via Ka band intersatellite links to relay communications to and from the terminals. The Iridium system uses these inter-satellite links to route traffic through space. Each of Iridium's satellites maintains links with two to four adjacent satellites, thereby creating a large mesh network. Hence, traffic from one Iridium terminal to another can be carried entirely through the space segment. If data needs to be exchanged with hosts that are not Iridium terminals, one of four earth stations is used to route into the Internet.

Iridium terminals generally use only low-gain antennas and do not require pointed parabolic dish antennas. This, of course was a major design criterion when Iridium was conceived for providing its mobile phone service with worldwide coverage. Unfortunately, this comes not without a price:
Firstly, the low earth orbit which results in rather short distances between satellite and terrestrial terminal and is required to keep free-space loss low, causes the need for a large fleet of satellites to provide continuous coverage. This large fleet is both costly to launch and maintain which results in high cost for the data traffic that has to be passed on to the user. Secondly, only very low data rates. Iridium claims data rates up to 10 kilobits per second for their "direct Internet" service. Furthermore, this data rate is stated for "compressible" data such as html-files. Reports are that actual data rates in the range of two to three kilobits per second are possible. In consequence, despite its undisputed advantageous in terms of robustness, Iridium was considered too slow and forbiddingly expensive for connecting the sensor stations.

Due to the large number of GITEWS sensor stations (see markers on Fig. 6), their more or less permanent but low rate data streams and the fact that these stations are not moving, the use of VSATs (Very Small Aperture Terminals) was considered a more economical solution. Such VSAT systems use parabolic "dish" antennas to achieve significant antenna gain and therefore do not require excessive transmission power despite the fact that the employed satellites are in geostationary orbit. In addition to the remote stations a central hub station, typically with a larger antenna is required. The operation of such hub stations is offered by a multitude of operators that typically pool many such stations on their premises and connect to their customers' premises using landline communications. While this service is convenient and would have relieved the project in terms of the necessary capacity building for operating an own hub on a daily basis, it was decided to install a dedicated hub at BMKG's headquarter in Jakarta. The rationale for this choice was that any 


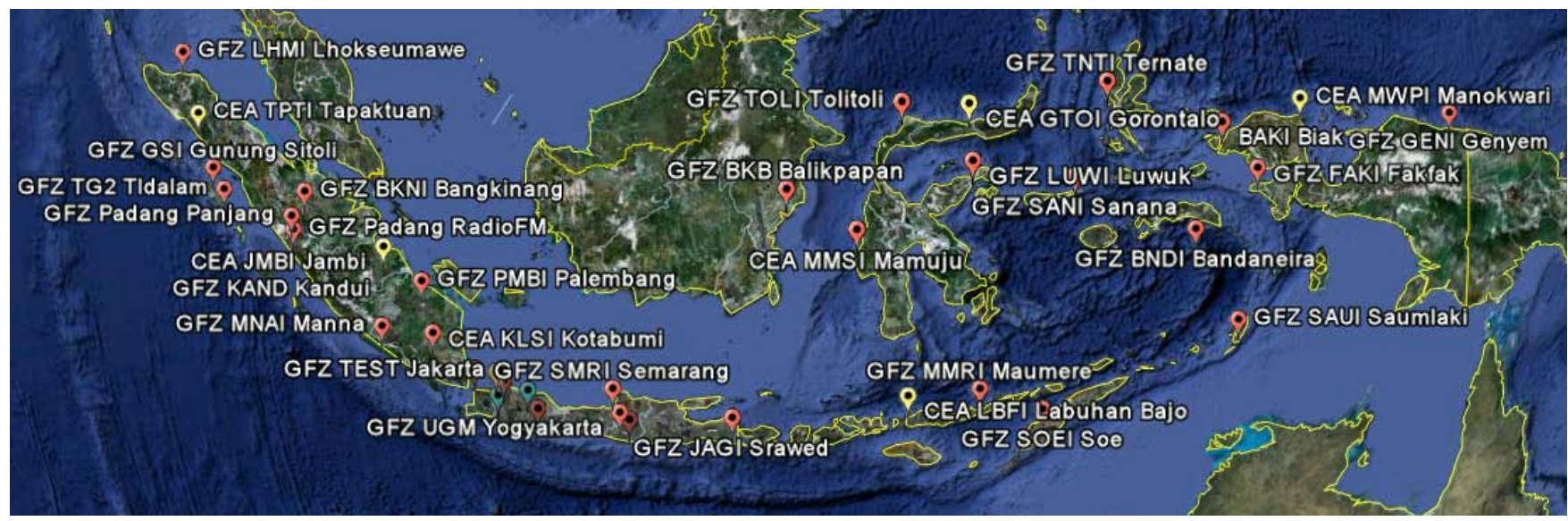

Fig. 6. Remote sensor stations of the GITEWS monitoring network in Indonesia.

other location than the actual warning center would involve at least two other possible points of failure (the offsite facilities where the hub would be placed and the landline or radio link between these facilities and the actual warning center) into the system and therefore make interruptions more likely. With the hub at BMKG we were able to minimize the number of involved components and links in order to minimize the likelihood of such interruptions. See Fig. 7 for an overview of all the satellite systems involved in the GITEWS project.

\section{Rain fading problem}

A well known issue for satellite communications in tropical regions like Indonesia is potentially heavy precipitation. The International Telecommunication Union (ITU) has categorized Indonesia as a Region P, which designates countries with very high rain precipitation. This condition has to be considered when deciding on the frequency bands to be used for the VSAT satellite communication links. Commercially available options (terminals and satellite transponders) are C-Band $(4-8 \mathrm{GHz})$ and $\mathrm{Ku} / \mathrm{Ka}(12-18 \mathrm{GHz} / 27-$ $40 \mathrm{GHz}$, respectively). Generally, rain attenuation increases with the frequency of the transmitted signal, making C-Band the standard band for reliable communication in tropic regions. However, the use of the Ku-band for satellite communications in Indonesia is becoming more frequent. According to Widodo (2005), several satellites (iPSTAR, MEASAT, Newskies NSS 6) above Indonesia have Ku-band transponders, and even Ka-band transponders.

Systems using frequencies above $10 \mathrm{GHz}$ suffer significantly from rain attenuation in terms of availability. This problem can be mitigated by planning for higher transmission power to compensate for rain fades. Table 5 gives an overview of issues considered for deciding the frequency band for sensor communication in GITEWS. Considering the extreme importance of the sensors in the warning chain the project chose the C-Band for achieving maximum availability.

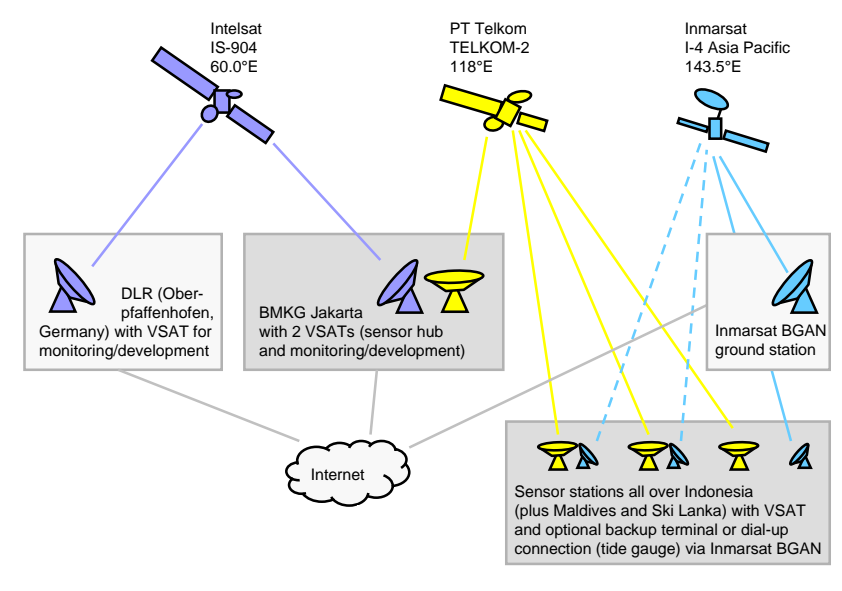

Fig. 7. Three satellite systems are used in GITEWS for different tasks.

In its current configuration the sensor communication system uses $1 \mathrm{MHz}$ of leased C-Band transponder bandwidth on the TELKOM2 satellite (see footprint on Fig. 8). This satellite is positioned on $118^{\circ}$ East in geostationary orbit and operated by the Indonesian satellite service provider Telkom.

\subsection{Allocation of system resources}

Based on the actual amount of data transferred to and from the sensor stations, the bandwidth has been partitioned into one downstream $(250 \mathrm{kHz}$, including inter-carrier spacing) and three upstreams $(250 \mathrm{kHz}$ each, incl. inter-carrier spacing).

The subnets with only $250 \mathrm{kHz}$ bandwidth allow to use relatively small parabolic antennas ( 1.8 meter diameter) and low power block up converters ( 2 Watt).

The VSAT hardware is a "5IF Hub", manufactured by VT iDirect, Incorporated. The iDirect hub was chosen for its extendibility with additional line cards which will allow extending the capacity of the system for further cooperation 


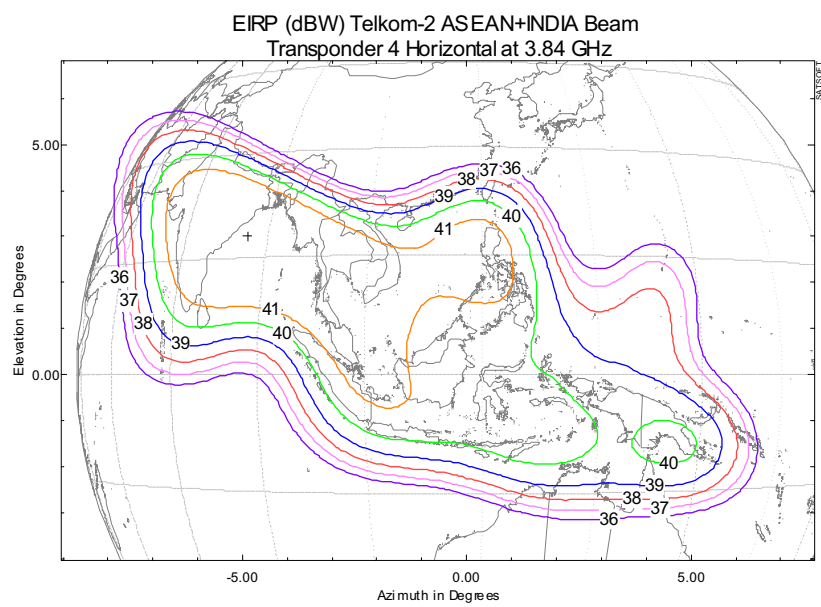

Fig. 8. Coverage area ("footprint") of the Telkom-2 Satellite, which is used for the sensor network from Maledives to Eastern Indonesia.

with additional partners extending the reach of the system's sensors. Furthermore, the system supports Virtual LAN (VLAN) subnets for security and bandwidth allocation which is particularly helpful in carrying network traffic of multiple international partners (China, Germany) and local Indonesian authorities (BMKG). In order to prevent the well-known problem of reduced throughput when TCP (Transport Control Protocol) is used on links with significant delay (the VSAT system has an inherent roundtrip delay of approx. $0.6 \mathrm{~s}$ ) the iDirect system employs TCP spoofing, i.e. sending "fake" acknowledgement packages to prevent TCP/IP stacks on the two involved hosts from throttling the data rate. The system also provides Quality of Service (QoS) control mechanisms for prioritizing specific data streams, such as from the most relevant sensors. This is particularly useful to avoid delaying or loosing such data in link congestions.

\subsection{Deployment issues}

Since a network of satellite terminals is a highly distributed and therefore inherently complex system to deploy and setup, some initial instabilities occurred and their causes were gradually removed during the initial parts of the learning curve. As an example, local radio interference was initially suspected of being the cause for instabilities during the initial setup. However, such local interferences were never verified and do not cause any problems, now.

Since March 2007 the system operates in a stable and efficient way. During the three years of operation some weather outages have occurred. So far, their frequency and durations are well within expectations.

Since there is typically no air conditioning equipment available at the sensor stations the equipments is operating at its temperature limits which may result in accelerated aging of some components. So far only few defects, but not necessarily caused by overheating, have occurred. Figures 9

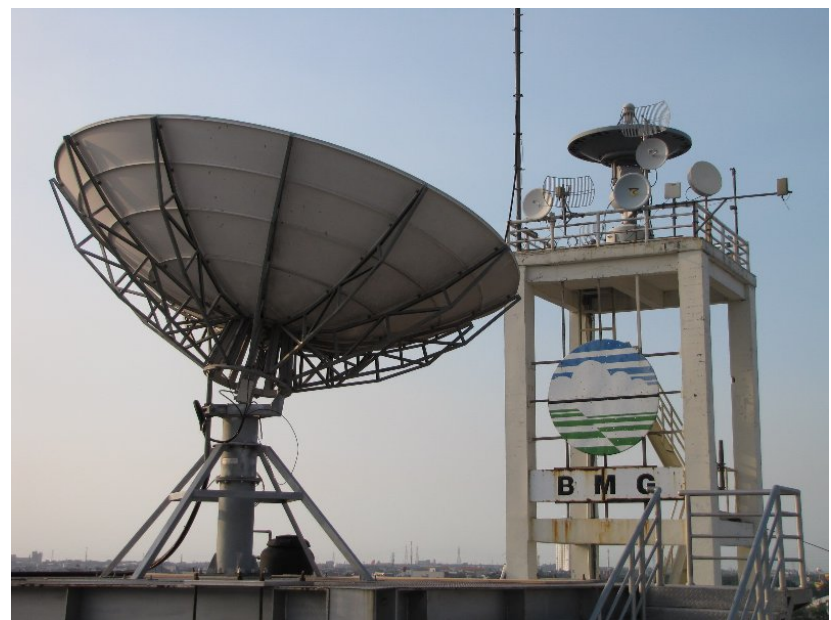

Fig. 9. $4.5 \mathrm{~m}$ antenna for the VSAT hub system in Jakarta since 2007.

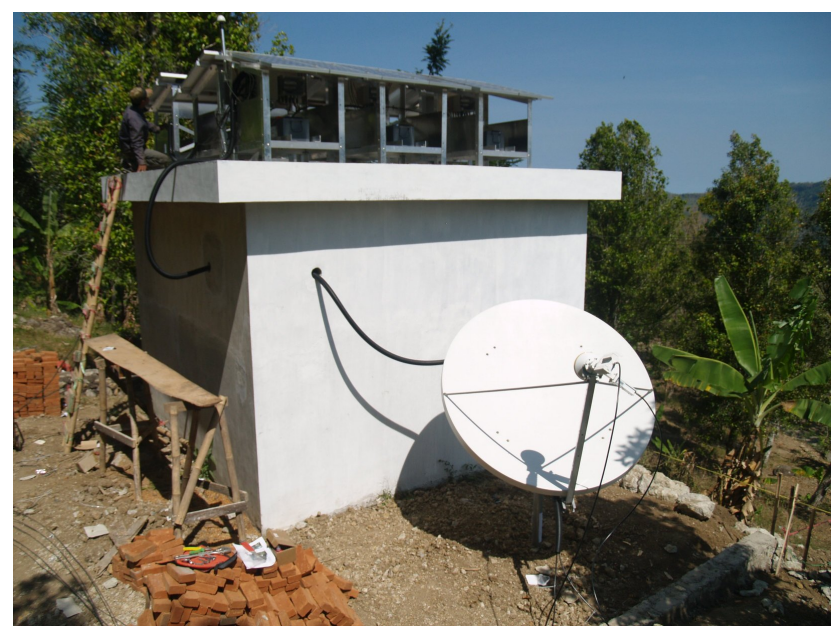

Fig. 10. Remote seismic sensor station with VSAT antenna in $\mathrm{Ci}$ sompet (south of Bandung, Java).

and 10 show the Hub antenna in Jakarta and a seismic sensor station with its satellite communication antenna in Cisompet.

\section{Backup communication link}

Due to the remoteness of the sensor stations and the difficulties in traveling to them, for example for debugging, it was considered economic to install additional backup communication links for maintenance and logging purposes. Among the options considered was the ACES/PASTI system as well as Inmarsat BGAN. The use of ACES/PASTI was investigated for its use as backup communication link and initial tests with hardware were carried out. Due to unsatisfying dial in performance, potentially due to instable spot beams, this system was not further integrated in favor of the Inmarsat BGAN service and terminals (Thrane \& Thrane Explorer 
Table 5. Selection of issues considered for deciding the frequency band for sensor communication in GITEWS.

\begin{tabular}{lll}
\hline & C-Band & Ku/Ka-Band \\
\hline Pros & - attenuation caused by rain lower, leading to & - smaller antennas \\
& higher link availability & - interference less likely \\
& - less expensive bandwidth & - less expensive equipment \\
Cons & - frequency region assigned to terrestrial & - potential dropout caused by heavy rain \\
& microwave systems which may cause & - more expensive bandwidth \\
& interference & \\
- more expensive equipment & larger antenna required $(>=1.8$ m) which & \\
& complicates transportation to remote areas & \\
\hline
\end{tabular}

110, formerly NERA Worldpro 1010). It is important to point out that while using BGAN as the primary communication means for the sensor stations would have been technically possible, it would have not been economically feasible. Using BGAN instead of the VSAT system to transmit the actual sensor data would have increased the traffic cost approximately by a factor of 100 for the seismic stations which generate approximately $10 \mathrm{kbit} / \mathrm{s}$ of traffic. However, due to the low amount of data sent by tide gauges (about $150 \mathrm{kByte}$ of uncompressed data per hour), BGAN is used on sensor stations with tide gauges.

Figure 11 shows the coverage areas of Inmarsat's three geostationary satellites and their individual spot beams. It can be seen that Indonesia and the part of the Indian Ocean relevant for the GITEWS project, lie well within the area covered by I-4 Asia Pacific.

\subsection{Operational experiences}

As stated earlier, satellite communication was chosen due to the vulnerability of terrestrial infrastructure such as landlines. However, an obvious question is whether the directional antennas of a VSAT-system are vulnerable to an earthquake, since their alignment towards the satellite might be affected by strong ground movement. Without being able to give a conclusive answer to this question we found the deployed VSAT-stations (antenna mount and alignment) to be very robust and, despite being considerably exposed to ground shaking ${ }^{2}$, not causing any problems. However, so far there is not enough evidence to state this as general rule.

The VSAT-based sensor communication system has been successfully deployed. So far, Germany has installed 30

\footnotetext{
${ }^{2}$ Examples are the Bengkulu Earthquake (12 September 2007) with magnitude 8.0 at $4.57^{\circ} \mathrm{S}, 101.34^{\circ} \mathrm{E}$ which did not cause any interruption to the nearest VSAT Station at Manna $\left(4.4^{\circ} \mathrm{S}\right.$, $\left.102.9^{\circ} \mathrm{E}\right)$ at a distance of approx. $150 \mathrm{~km}$ and the Padang Earthquake (30 September 2009) with magnitude 7.7 at $0.78^{\circ} \mathrm{S}, 99.87^{\circ} \mathrm{E}$ which did not cause any interruption at the nearest VSAT Station at Telukdalam, Nias Island $\left(0.6^{\circ} \mathrm{N}, 97.8^{\circ} \mathrm{E}\right)$ at a distance of approx. $230 \mathrm{~km}$.)
}

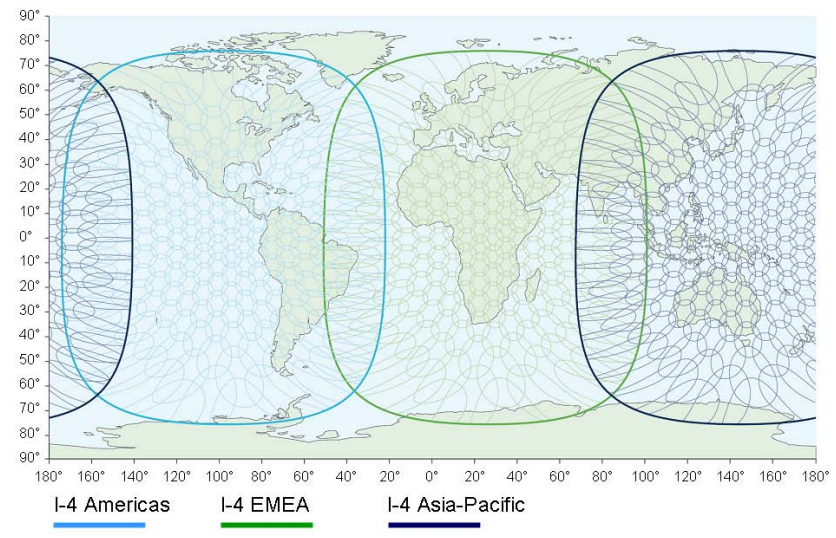

Fig. 11. Coverage areas of Inmarsat's three geostationary satellites and their individual spot beams. Indonesia and the part of the Indian Ocean relevant for the GTEWS project, lie well within the area covered by I-4 Asia Pacific.

VSATs for connecting the system's sensors (seismic, GPS, tide gauges) in three countries. From today's perspective the final configuration of 35 stations foreseen in GITEWS will not exceed the system's capacity. Moreover, China currently operates 8 seismic stations over the installed VSAT system and is planning for a final configuration of 10 . BMKG currently operates two test stations over the VSAT system for feasibility checks. One of the two test stations is equipped with a magnetism sensor. The second test station is equipped with a lightning sensor. These feasibility checks are carried out in preparation to a planned installation of a network of such sensors in the period from 2011 to 2012.

Since April 2009 the VSAT hub is successfully operated and monitored by local BMKG staff which is considered to be a further example of successful capacity building in GITEWS. 


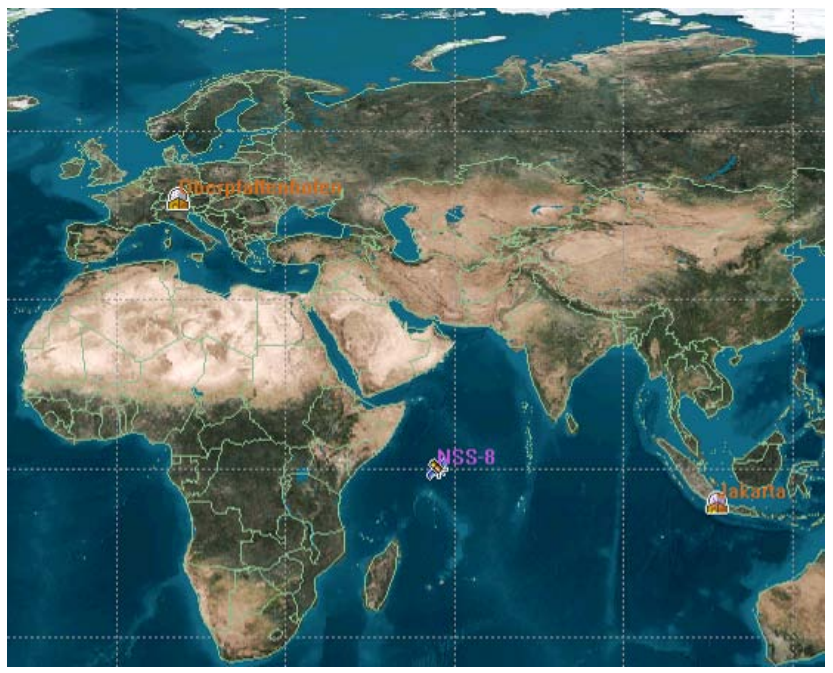

Fig. 12. INTELSAT IS-904, positioned in geostationary orbit at $60^{\circ}$ East, well between Oberpfaffenhofen $\left(48^{\circ} 4^{\prime} \mathrm{N}, 11^{\circ} 16^{\prime} \mathrm{O}\right)$ and Jakarta $\left(6^{\circ} 11^{\prime} \mathrm{S}, 106^{\circ} 50^{\prime} \mathrm{O}\right)$.

\section{Center-to-center communication}

Already in the definition phase of the GITEWS project it had been planned that the warning system would have to be designed for fully autonomous operation by Indonesian authorities. As such, no essential elements of the warning chain were to be located in Germany. Nevertheless, it was decided that a reliable communication link between the warning center in Jakarta and the partner institutions in Germany would be needed for a number of reasons during the installation phase: firstly, during the installation phase of the system software components would have to be deployed, monitored and debugged. A physical presence of all involved software developers in Jakarta for every update cycle of the software was not feasible due to the significant amount of travel involved. Secondly, it was considered important to have immediate and detailed information about the system's status in the case of significant seismic events that were processed by the system, thereby facilitating rapid analysis of the system's performance by its developers.

Initially, it was not clear whether all sensor data would be directly delivered to the main warning center at Jakarta, or if regional warning centers would aggregate and preprocess sensor data, potentially issuing warning themselves, and forward their findings to the main warning center.

\section{Configuration of the satellite communication system}

For similar reasons already discussed in the previous section on the sensor communication, a VSAT based communication system was chosen as the most economic solution that would guarantee sufficient reliability and flexibility for further extensions of the system.
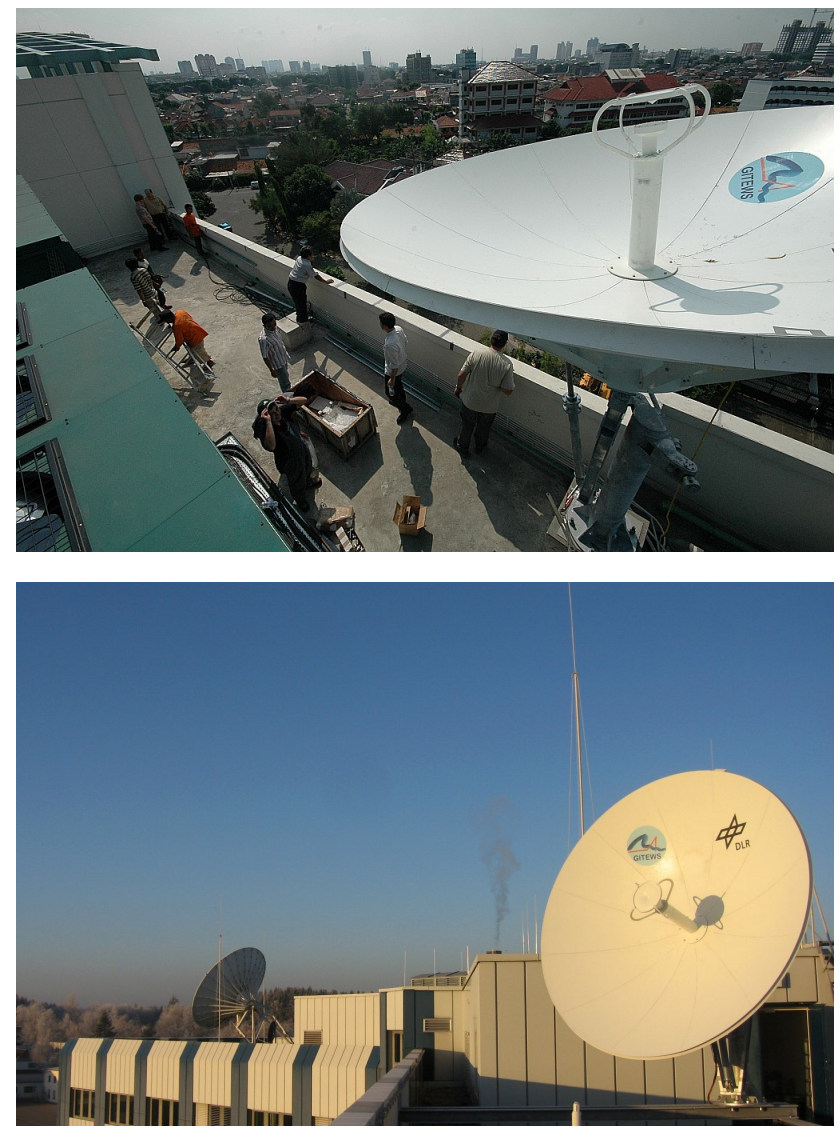

Fig. 13. The two VSAT antennas on the roof of BMKG headquarters in Jakarta (top) and on a building of DLR in Oberpfaffenhofen (bottom).

The chosen hardware (SkyWAN, manufactured by NDSatCom) for the two ground stations in Jakarta and Oberpfaffenhofen uses QPSK (Quadrature Phase Shift Keying) modulation and a TDMA (Time Division Multiple Access) scheme. Both stations are equipped with fixed parabolic antennas with a diameter of $3.7 \mathrm{~m}$. As the system has to bridge the wide gap between DLR's site in Oberpfaffenhofen $\left(48^{\circ} 4^{\prime} \mathrm{N}, 11^{\circ} 16^{\prime} \mathrm{O}\right)$ and BMKG in Jakarta $\left(6^{\circ} 11^{\prime} \mathrm{S}, 106^{\circ} 50^{\prime} \mathrm{O}\right)$ a satellite had to be found that provides coverage for both locations.

Since a single beam would not be able to cover both locations with sufficient power density, it is necessary to employ two beams and to "cross-strap" the corresponding transponders. The system currently uses INTELSAT IS-904, positioned in geostationary orbit at $60^{\circ}$ East (Fig. 12). The ground stations in Jakarta and Oberpfaffenhofen (Fig. 13) were installed in early 2008 and have been successfully operated since this time. 


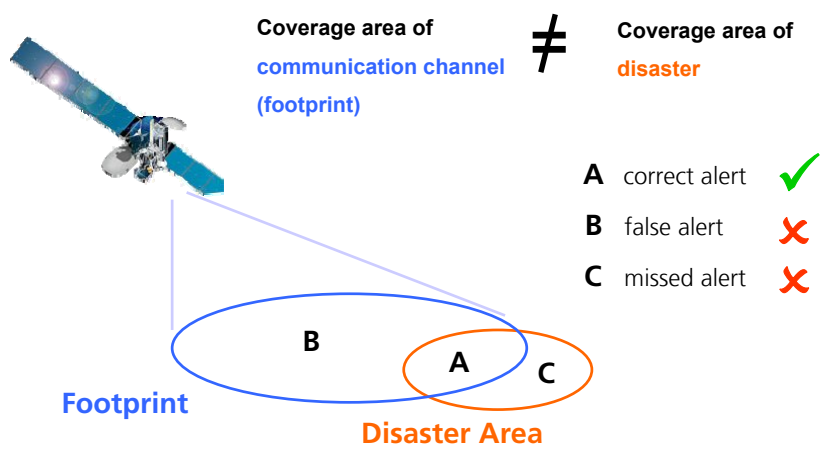

Fig. 14. A mismatch of the affected area with the coverage area of the communication channel utilized to transport the warning leads to missed alerts and false alerts.

\section{Warning dissemination}

It was decided upon the definition of the GITEWS project, that the dissemination of the warnings would be finally left to Indonesian authorities. However, conceptual work was carried out in order to understand the requirements a dissemination system would have to fulfill and how it would interface with the rest of the warning system.

Again the guidelines set forth by UN-ISDR provide a good starting point:

\section{Dissemination and Communication. \\ "Warnings must reach those at risk. Clear mes- sages containing simple, useful information are critical to enable proper responses that will help safeguard lives and livelihoods. Regional, na- tional and community level communication sys- tems must be pre-identified and appropriate au- thoritative voices established. The use of multiple communication channels is necessary to ensure as many people as possible are warned, to avoid fail- ure of any one channel, and to reinforce the warn- ing message". \\ "Warning alerts and messages tailored to the spe- cific needs of those at risk (e.g. for diverse cul- tural, social, gender, linguistic and educational backgrounds). Warning alerts and messages are geographically-specific to ensure warnings are targeted to those at risk only". (UN-ISDR, 2006b).}

Following these guidelines, we adopted a human-centered perspective in our analysis in order to derive requirements. In general, disasters do not favor certain times of the day. Hence, we have to be able to warn people whether they are at home, at work, indoors, outdoors, awake, or asleep. Even in economically wealthy countries it is extremely difficult to achieve high penetration rates if users have to procure a dedicated device for receiving warnings. This effect is even more aggravated in less developed countries. Ideally, devices that

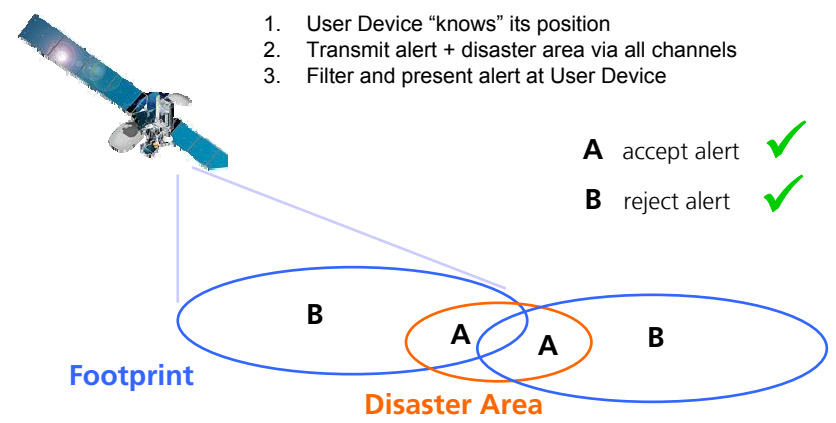

Fig. 15. If a device is capable to determine its location and if the affected region is encoded and transmitted via multiple communication channels, missed and false alerts can be avoided.

are already deployed for other purposes are employed for signaling to the user. Users may be in possession or proximity of analog radio (FM, AM), analog and digital TV (terrestrial, cable, and satellite), telephones, mobile phones, or computers connected to the Internet.

\section{Requirements}

The impact of a specific disaster has impact on a geographically defined region, whereas other regions are not affected. In order to keep responsiveness to warnings at a high level it is important to avoid giving false alarms. Accordingly, warnings have to be limited to affected regions or else they become false alarms in unaffected regions (see Figs. 14 and 15). Some channels are inherently limited to relatively small regions (e.g. FM radio), some are not (e.g. Internet access, satellite TV). In order to be useful for disseminating warnings, a channel has to be able to transport alert messages. Ideally, a channel is also able to transmit a wake-up signal to receiving devices.

An ideal device would be capable to determine its location, either by manual input manual, satellite navigation) in order filter alerts based on specified region and its own location as well as alert levels before presenting alerts to its user(s).

\section{Implementation aspects for data communication within the central warning center and sensor stations}

\subsection{Power consumption and supply}

The most crucial, yet often difficult prerequisite for reliable data communication is reliable power supply for all components that are involved in the communication chain. While it is relatively straightforward to install uninterruptible power supplies (UPS) and backup generators in cities like Jakarta, this is not always an option at sensor stations that are mostly located in remote areas. 


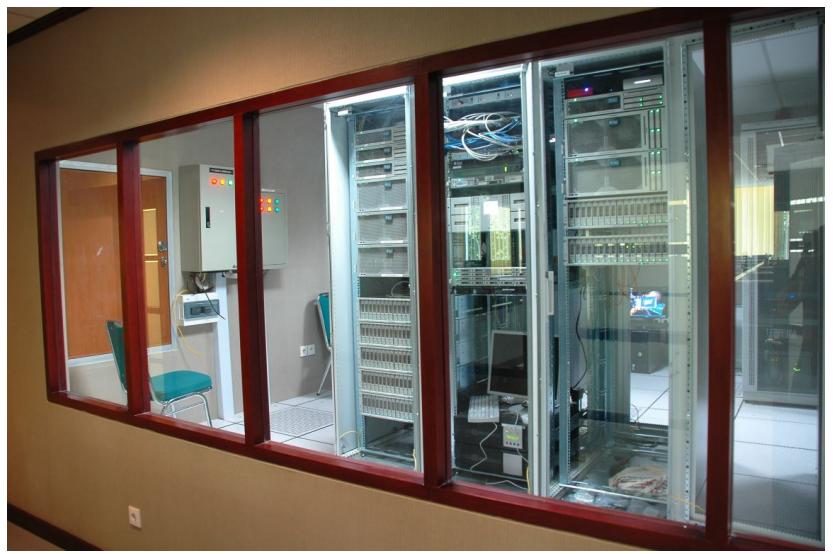

Fig. 16. Local infrastructure in the warning center in Jakarta for the processing systems in the server room.

Due to temporary power cuts and electrical surges that are common in Jakarta, a UPS is indispensable and needs to be well dimensioned from the very beginning of the planning. In consequence, a detailed planning for the power infrastructure in the server room in Jakarta (see picture on Fig. 16) was necessary. Network equipment usually does not consume much power (except for combined Power over Ethernet devices). However, servers can be upgraded at a later point in time with additional processors, which may increase their power consumption considerably. This has to be taken into account for the dimensioning of a UPS - especially concerning hold time of the batteries for a complete shutdown sequence in case the generator is not able to start.

It is mandatory, that local network devices are available at any time during an electrical power outage because shutdown sequences and monitoring commands are mainly sent over the network. If possible, servers and network should be connected to independent UPS's for easier debugging and management. The use of devices with two power adapters for redundancy is recommended, too.

While the sensor stations and their measurement equipment are already optimized for low power consumption, the additional satellite links require a certain minimum power to reach the satellite at a certain data rate (link budget). The focus at the remote stations is not to ensure 24/7/365 operating time - the loss of one or two stations for some days can be coped with due to the fact that there are many stations worldwide. Nevertheless, the power budget for an active station posed a major problem in the beginning of the project especially for the stations that are exclusively solar-batterypowered like the one in Fig. 17. For details on the implementation, see the corresponding publication of the seismic working group. Still, power issues arise in the daily work: cables are often disconnected by mistake from local people and batteries need replacement after some years.

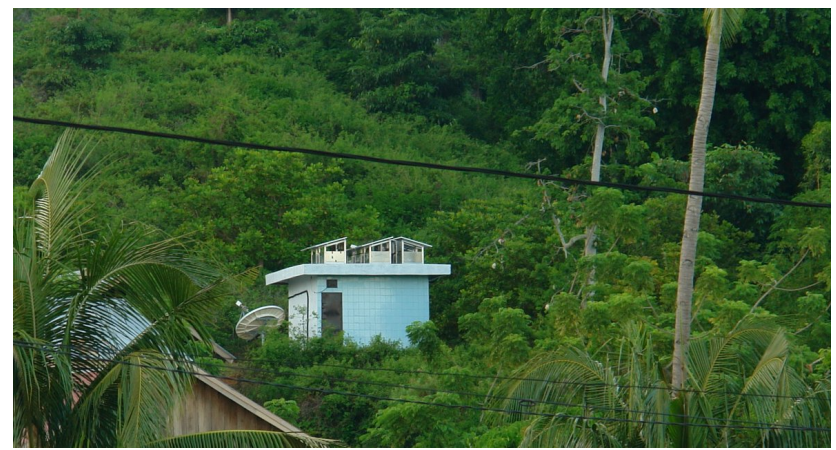

Fig. 17. Remote seismic sensor station with solar panels for the power supply of the sensors, the processing system and the communication link (Sanana, Moluccas Islands).

\subsection{Network health monitoring and backbone}

As the number of devices (stations, servers and network components) rapidly reached a number of 150 , it is clear that any kind of monitoring of the health of the network and devices is necessary from the beginning and should be continuously adapted to the changing hardware situations and software configurations. This enables to identify bottlenecks caused by modified configurations or ineffective applications.

Additional sensors (temperature, humidity, power consumption) are integrated in the monitoring. Furthermore, traffic statistics for network equipment are always helpful for debugging. Our tools of choice are MRTG (http://oss. oetiker.ch/mrtg/) for network traffic analysis and NAGIOS (http://www.nagios.org/) for monitoring of device and service availability.

Another important component is the routing equipment, which interconnects several different networks. In GITEWS like in other complex high availability systems, there are numerous data paths for all the involved systems and we use several logical networks to separate or combine these data paths. On the one hand it is important to prevent unauthorized access between some networks and on the other hand, we need a very flexible system concerning network connectivity. Changing parameters like the numbers of stations, the use of virtual LANs (Local Area Networks) or numerous network ports at the servers require highly flexible routing and switching hardware at any time of the project.

The work with the data communication infrastructure showed, that in a rapidly changing complex project environment with many different sensor systems and server components, the requirements cannot be defined at the very beginning. All systems were still under development and had to be integrated step by step. Interfacing the devices to existing infrastructure (power and data networks at BMKG Jakarta) brings up new challenges, daily, further emphasizing the need for qualified people on site on a long term basis. 


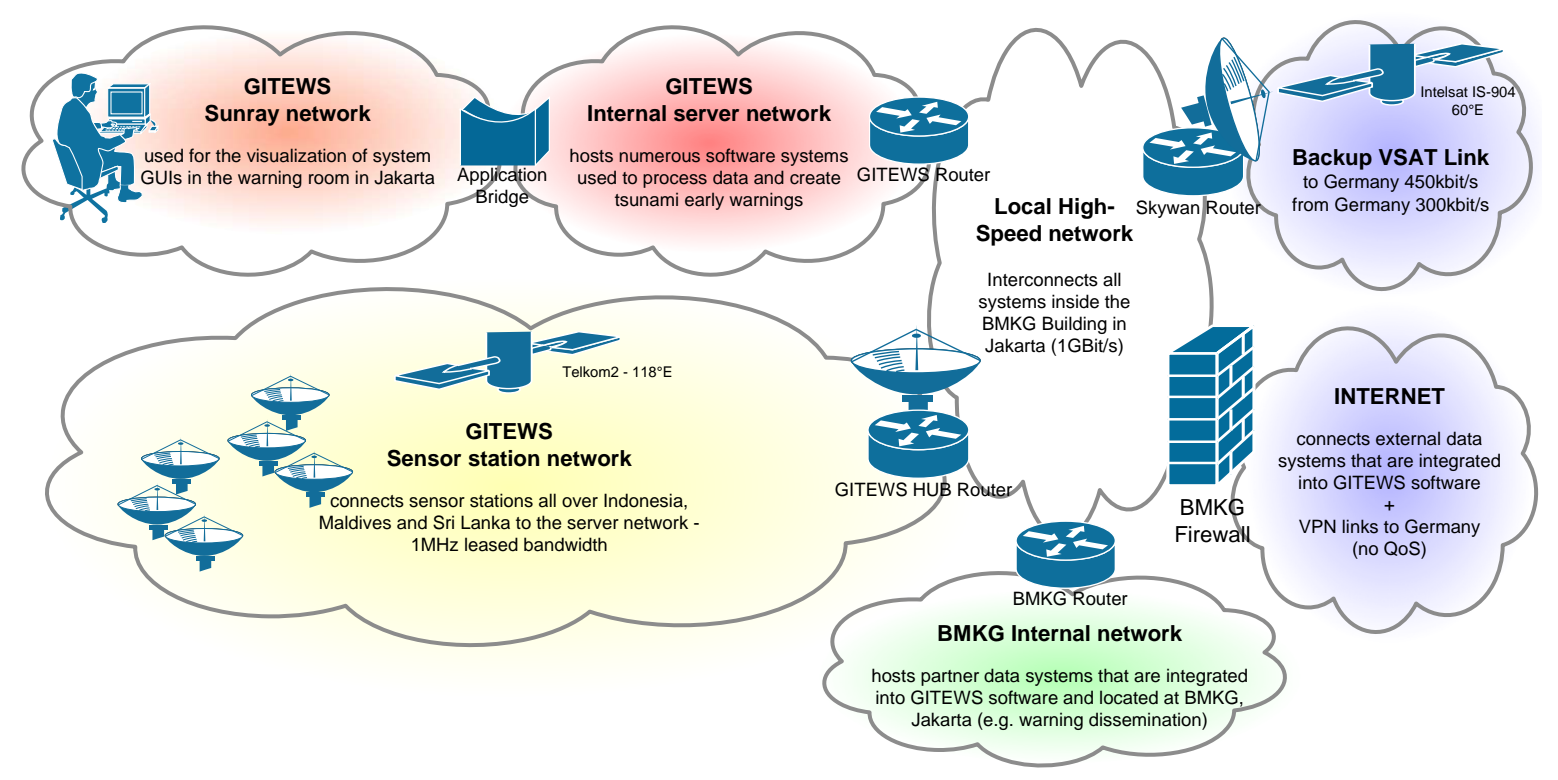

Fig. 18. Components and interconnections used in the warning system.

\section{Conclusions and outlook}

During the years 2006-2010 an effective, cost efficient and sustainable communication infrastructure for a tsunami early warning system has been conceived, designed and deployed (see Fig. 18 for a detailed illustration of the components and interconnections used in GITEWS). This communication infrastructure encompasses the "convergent" part of sensor communication, a reliable data link between Jakarta and Oberpfaffenhofen and concepts for the dissemination of warnings. While the system is fairly large it is still a regional warning system that - in its current stage - does not fully implement the communication architecture of the generic warning system described in Sect. 1. Instead, the current communication system implements only the required functionality for the scope of the GITEWS project. Nevertheless, we strived for a system design and components that are capable of growing into a more global system with wider geographic span and potentially more distributed decision processes.

In the first part of this paper, we have mainly discussed the reasons for using multiple different satellite communication channels (e.g. backup) in a distributed warning system and how they were implemented in our special environment. In general, today's available satellite communication systems are still complex to set up and configure (especially at the hub or master station), but very robust to environmental influences and easy to operate.

Furthermore, we dealt with a range of infrastructure details, which came up during the process of installation and testing. Major sources of problems were electrical power issues - not only at the remote sensor stations. We would expect similar issues for almost any other similar warning system with remotely distributed sensor stations or partially unreliable power distribution grids. In fact, observing power outages during the installation phase is a good alarm-call to plan for expected power outages in case of a natural disaster. To address these problems, the use of redundant systems of any kind (power supply, backup batteries, solar energy, uninterruptible power supply, backup data links, and more) is strongly recommended wherever possible. Of course, the long term stability of the involved components, specifically in the light of Indonesian climate conditions still needs to be proven. Both the importance of the communication systems in a warning system and the cost and effort involved in their deployment is easily underestimated (see example on Fig. 19).

To verify the initial assumptions about data rates and availability of devices and (satellite) network links, the use of monitoring tools of any type is recommended from the very beginning of installation work. We found that often users and developers are not fully aware of the strong constraints in satellite bandwidth and the involved cost. Additionally the best-effort network "internet" may have unpredictable restrictions. We found it crucial to clearly communicate these limitations from the beginning of the overall system design. This allows software and system developers to take these limitations into account, minimize data traffic and avoid link congestion problems a later state.

The daily communication with the partners in Indonesia, the quick adaptation of required configuration changes, and prompt troubleshooting not only concerning networks was also omnipresent in our work and lead to the necessity of having people on site during the whole time of the built-up and testing phase of the project. The presence of these experts 


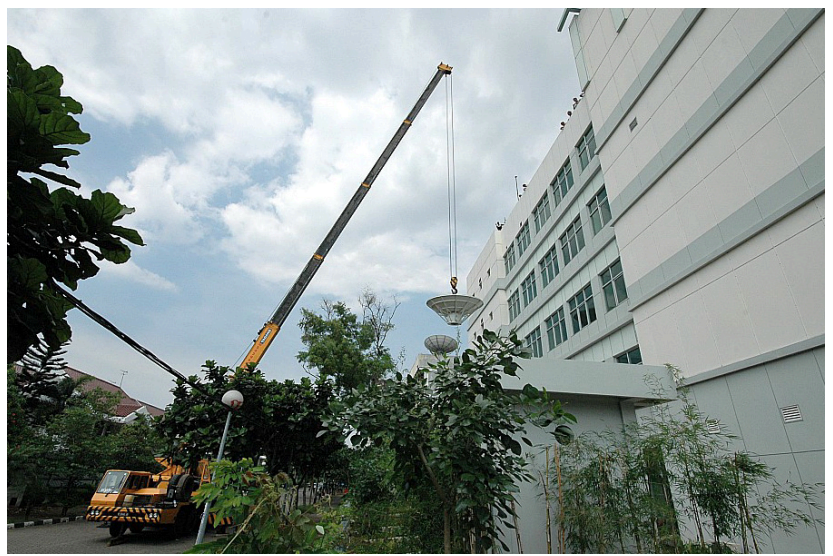

Fig. 19. The term "VSAT" (Very Small Aperture Terminal) may be misleading: considerable logistical effort was involved in the deployment of both the sensor and center to center communication links.

can be seen as a key factor for the successful implementation of a highly distributed and complex system like the one installed in the GITEWS project. Hence we further recommend to permanently stationing liaison persons with local authorities for projects of similar scale.

\section{Outlook}

For future warning systems that might be conceived and deployed for natural disasters in other regions e.g. in Europe, it would be desirable to utilize existing infrastructures such as the public Internet. A detailed analysis of its vulnerability and resilience to natural disasters would be most valuable. Where such existing infrastructures prove to be sufficiently reliable, they should be used. For other regions smaller, less expensive and less power consuming satellite based communication terminals would be desirable.

We believe that many of the issues we encountered during our work in the GITEWS project (German Indonesian Tsunami Early Warning System) on the design and implementation communication architecture are relevant for other types of warning systems. We hope that our work will help in empowering people in Indonesia to reduce the possibility of personal injury, loss of life and damage to property and the environment as well as provide useful insights for the development of further worldwide warning systems.

Acknowledgements. The GITEWS project (German Indonesian Tsunami Early Warning System) is carried out through a large group of scientists and engineers from GFZ, German Research Centre for Geosciences (consortium leader) and its partners from, the Alfred Wegener Institute for Polar and Marine Research (AWI), the German Aerospace Center (DLR), the GKSS Research Centre, the German Marine Research Consortium (KDM), the Leibniz Institute for Marine Sciences (IFM-GEOMAR), the United Nations University (UNU), the Federal Institute for Geosciences and Natural Resources
(BGR), the German Agency for Technical Cooperation (GTZ), as well as from Indonesian and other international partners. Funding is provided by the German Federal Ministry for Education and Research (BMBF), Grant 03TSU01.

The authors would like to thank the anonymous reviewers and the editors for their helpful comments on an earlier draft of this manuscript.

Michael Günther would like to thank CIM (Centre for international Migration and Development), part of GTZ Germany, for enabling and supporting his embedding in Indonesia.

Edited by: U. Münch

Reviewed by: E. Leitgeb and another anonymous referee

\section{References}

Angermann, M.: Kommunikations- und Informationstechnologien im Katastrophenfall, VDE-Kongress 2006, Aachen, Deutschland, 2006

BBC News 2008-01-31: Severed cables disrupt Internet, available at: http://news.bbc.co.uk/2/hi/7218008.stm, 2008.

Bloomberg 2008-12-19: Severed Cables in Mediterranean Disrupt Communication, available at: http://www.bloomberg.com/apps/ news?pid=newsarchive \&sid=aBa01TN.dcoQ, 2008.

Meinig, C., Stalin, S. E., Nakamura, A. I., González, F., and Milburn, H. G.: Technology Developments in Real-Time Tsunami Measuring, Monitoring and Forecasting. In Oceans 2005 MTS/IEEE, 19-23 September 2005, Washington, DC, available at: http://nctr.pmel.noaa.gov/pubs.htm, 2005.

Pine, J. C.: Technology in Emergency Management, John Wiley \& Sons, 2007.

Rudloff, A., Lauterjung, J., Münch, U., and Tinti, S.: Preface "The GITEWS Project (German-Indonesian Tsunami Early Warning System)”, Nat. Hazards Earth Syst. Sci., 9, 1381-1382, doi:10.5194/nhess-9-1381-2009, 2009.

Spahn, H., Hoppe, M., Vidiarina, H. D., and Usdianto, B.: Experience from three years of local capacity development for tsunami early warning in Indonesia: challenges, lessons and the way ahead, Nat. Hazards Earth Syst. Sci., 10, 1411-1429, doi:10.5194/nhess-10-1411-2010, 2010.

Tu, Y.: How robust is the Internet?, Nature 406, 353-354, http: //www.nature.com/, 2000.

UN-ISDR: Developing Early Warning Systems: A Checklist, Third Early Warning Conference, 27-29 March, 2006, Bonn, Germany, 2006a.

UN-ISDR: Compendium of Early Warning Projects, Third Early Warning Conference, 27-29 March, 2006, Bonn, Germany, 2006b.

Widodo, P. S.: It is time to use the Ku-band in Indonesia, Online Journal of Space Communication, ssue No. 8: "Regional Development: Indonesia”, available at: http://spacejournal.ohio.edu/ issue8/pers_setiyanto.html, 2005.

Zschau, J. and Küppers, A. (ed.): Early warning systems for natural disaster reduction, Springer, Berlin, 2003. 